JMK: JURNAL MEDIA KESEHATAN

P-ISSN : 1979-5750

E-ISSN : 2654-5705

\title{
PENGARUH PENDIDIKAN KESEHATAN MENGGUNAKAN MEDIA VIDEO ANIMASI TERHADAP KESIAPAN IBU HAMIL DALAM MENGHADAPI PERSALINAN
}

\author{
Lisnawati ${ }^{1)}$, Dara Linggar Adi Prahastuti1) \\ ${ }^{1}$ Jurusan Kebidanan, Poltekkes Kemenkes Tasikmalaya \\ ${ }^{2}$ Jurusan Kebidanan, Poltekkes Kemenkes Tasikmalaya \\ Email : bidan_lisna85@yahoo.com
}

\begin{abstract}
Problems : The indirect cause of maternal death is that there are still many late cases. Case 3 is late, including: being late in recognizing the danger signs of childbirth and making decisions, being referred too late to a health facility, being late being handled by health workers at a health service facility. Readiness in the face of childbirth is one solution to prevent maternal death. The Aim Of The Research: to determine the effect of health education using video media on the readiness of pregnant women in facing childbirth in the working area of UPTD Puskesmas Talun, Cirebon Regency. Research Method: The research design used a quasi-experimental design with pretest and posttest with one group design. The sampling technique was carried out by nonprobability sampling technique. Sampling used a total sampling technique (30 pregnant women) in the second and third trimesters. Bivariate analysis using Wilcoxon test. The Results: The results of the pre test and post test showed an increase. The effect of health education using video media on mother's readiness in facing childbirth ( $p$ value $=0.000)$. Conclusion: There is an effect of health education using video media on the readiness of pregnant women in facing childbirth.
\end{abstract}

Keywords: Health Education Using Video Media, Readiness, Pregnant Women

\begin{abstract}
ABSTRAK
Permasalahan: Penyebab tidak langsung kematian ibu adalah masih banyaknya kasus 3 terlambat. Kasus 3 terlambat, meliputi : terlambat mengenali tanda bahaya persalinan dan mengambil keputusan, terlambat dirujuk ke fasilitas kesehatan, terlambat ditangani oleh tenaga kesehatan di fasilitas pelayanan kesehatan. Kesiapan dalam menghadapi persalinan merupakan salah satu solusi untuk mencegah kematian pada ibu. Tujuan : untuk mengetahui pengaruh pendidikan kesehatan dengan menggunakan media video terhadap kesiapan ibu hamil dalam menghadapi persalinan di wilayah kerja UPTD Puskesmas Talun Kabupaten Cirebon. Metode : Rancangan penelitian menggunakan quasi experiment dengan pretest and posttest with one group design. Teknik pengambilan sampel dilakukan dengan teknik Non - probability sampling. Pengambilan sampel menggunakan Teknik total sampling (30 ibu hamil) pada trimester II dan III. Analisis bivariat menggunakan Uji Wilcoxon. Hasil : Hasil pre test dan post test menunjukkan adanya peningkatan nilai kesiapan dalam menghadapi persalinan, yaitu nilai median sebelum $=49($ minimal $=46$, maksimal $=56)$ sedangkan median sesudah $=57$ ( minimal $=53$, maksimal $=63)$. Analisis pengaruh pendidikan kesehatan menggunakan media video terhadap kesiapan ibu dalam menghadapi persalinan $(p$ value $=0,000)$. Kesimpulan :Terdapat pengaruh pendidikan kesehatan menggunakan media video terhadap kesiapan ibu hamil dalam menghadapi persalinan.
\end{abstract}

Kata Kunci : Pendidikan Kesehatan Menggunakan Media Video, Kesiapan, Ibu Hamil 


\section{PENDAHULUAN}

Penyebab kematian langsung ibu di Indonesia didominasi oleh perdarahan pasca persalinan, hipertensi/eklamsia, dan infeksi. Penyebab tidak langsung kematian ibu adalah masih banyaknya kasus 3 terlambat. Kasus 3 terlambat, meliputi : terlambat mengenali tanda bahaya persalinan dan mengambil keputusan, terlambat dirujuk ke fasilitas kesehatan, terlambat ditangani oleh tenaga kesehatan di fasilitas pelayanan kesehatan (GKIA, 2016). Dari kasus 3 terlambat salah satunya bisa di cegah dengan kesiapan dalam menghadapi persalinan. Sebagai gambaran pada hasil penelitian menunjukkan bahwa hasil kesiapan responden yang merasa siap menghadapi persalinan berjumlah $56.5 \%$, dan yang tidak siap dalam menghadapi persalinan sebanyak 43.5\%. (Yeva Yuni, 2017)

Kesiapan fisik berkaitan dengan masalah kondisi kesehatan ibu, dimana ibu perlu menyiapkan kondisi fisik sebelum hamil. Ibu memahami berupa adanya perubahan fisiologi sebelum terjadi persalinan kira-kira 2 minggu, dimana ibu akan lebih mudah bernafas karena fundus uteri agak menurun berhubung kepala janin mulai masuk ke dalam pintu atas pinggul (PAP), Ibu akan sering buang air kecil (BAK) karena turunnya kepala janin ke dalam PAP yang menekan vesika urinaria serta ibu merasakan adanya gambaran his palsu yaitu kadangkadang perut mengejan. Keluarga baik dari orang tua maupun suami merupakan bagian terdekat bagi calon ibu yang dapat memberikan pertimbangan serta bantuan sehingga bagi ibu yang akan melahirkan merupakan motivasi tersendiri sehingga lebih tabah dan lebih siap dalam menghadapi persalinan. Dukungan dari suami dan keluarga untuk membantu pemahaman seorang ibu hamil mendapat pengalaman sehingga ibu hamil dapat mengantisipasi dan lebih baik dalam menghadapi kebutuhan ibu. Kebutuhan komunikasi dan harapan suami dan anggota keluarga yang lain menjadi sumber dukungan yang dibutuhkan ibu hamil untuk mendukung fungsi kesehatan keluarga (Joyce Y, 2014).

Salah satu upaya untuk meningkatkan kesiapan ibu dalam menghadapi adalah dengan memberikan edukasi atau informasi mengenai persiapan persalinan. Dari program pemerintah sendiri telah berjalan seperti kelas ibu hamil dan P4K (Perencanaan Persalinan dan Pencegahan Komplikasi). Di kelas ibu hamil cakupannya dari saat hamil hingga masa nifas, termasuk juga dalam persiapan persalinan. Sedangkan P4K yaitu dengan pemasangan stiker P4K yang didalamnya tertera beberapa informasi yang memudahkan bidan desa dalam 
bertugas. Namun dari pemerintah itu sendiri belum menggunakan penyuluhan untuk mengetahui kesiapan ibu hamil dalam menghadapi persalinan (Kemkes RI, 2011).

Penyelenggaraan penyuluhan perlu menggunakan media agar pesan yang ingin disampaikan menjadi tersampaikan ke peserta penyuluhan. Media dibagi menjadi tiga yaitu audio, visual, dan audio-visual. Contoh media visual: a) foto; b) grafik; c) poster; dll. Contoh media audio: a) laboratorim bahasa; b) radio; c) alat perekam; dll. Contoh media audiovisual; a) televisi; b) film bersuara; c) video kaset/video. Semakin banyak alat indera dipakai, semakin mudah memahami. Media video merupakan media yang efektif dalam penyampaian informasi pendidikan kesehatan reproduksi. Promosi kesehatan menggunakan media video dapat meningkatkan pengetahuan dan sikap. (Ambarwati et al., 2014)

Berdasarkan data Puskesmas Talun terhitung pada bulan September hingga Desember terdapat $122 \mathrm{ibu}$ hamil. Studi pendahuluan yang dilakukan pada bulan November 2020 di Puskesmas Talun dengan wawancara langsung diketahui 2 bidan dan 8 ibu hamil trimester II dan III belum pernah mengadakan/mendapatkan penyuluhan mengenai persiapan persalinan menggunakan media video. Puskesmas Talun memiliki program Kelas Ibu Hamil.

Program ini mengajak ibu hamil untuk meningkatkan pengetahuan, merubah sikap dan perilaku ibu agar memahami tentang kehamilan, perubahan tubuh dan keluhan selama kehamilan, perawatan kehamilan, persalinan, perawatan nifas, dan lain lain, namun program Kelas Ibu Hamil ini kegiatannya berjalan kurang lancar dan belum ada evaluasi lebih lanjut. Dari beberapa video yang pernah peneliti lihat di Puskesmas tersebut, hanya fokus pada beberapa persiapan persalinan. Penelitian ini diharapkan dapat menjadi alternatif yang dapat digunakan untuk memberikan Pendidikan Kesehatan khususnya tentang persiapan persalinan dengan cara yang menarik dan menyenangkan yaitu dengan video animasi persiapan persalinan.. Maka dari itu peneliti membuat video yang cakupan persiapan persalinannya lebih luas, tidak hanya fokus pada persiapan tertentu.

Berdasarkan hasil wawancara pada ibu hamil trimester II dan III yang dilakukan di Puskesmas Talun didapatkan bahwa ketika ingin bersalin tidak memiliki persiapan seperti transportasi rujukan, tidak memiliki pendonor darah, dan persiapan materi lainnya. Serta hasil survey didapatkan bahwa metode yang digunakan untuk pemberian informasi tentang persiapan persalinan adalah menggunakan media buku KIA. Media video belum pernah 
digunakan oleh Puskesmas Talun dalam persiapan persalinan. Penelitian ini bertujuan untuk mengetahui "Pengaruh pendidikan kesehatan menggunakan media video terhadap kesiapan ibu hamil dalam menghadapi persalinan di wilayah kerja UPTD Puskesmas Talun Kabupaten Cirebon Tahun 2021”.

\section{METODE PENELITIAN}

Merupakan penelitian kuantitatif menggunakan quasi eksperimen dengan pendekatan "Pretest-Posttest one group design" yaitu dengan cara memberikan pre test (pengamatan awal) dengan memberikan intervensi edukasi dengan penyuluhan dan diberikan post test setelah diberikan intervensi. Populasi adalah seluruh ibu hamil yang berjumlah $122 \mathrm{ibu}$ hamil, sedangkan pengambilan sampel menggunakan Teknik purposive sampling, sebanyak 30 ibu hamil trimester II dan III di wilayah kerja UPTD Puskesmas Talun Kabupaten Cirebon (Jawa Barat) tahun 2021. Instrumen yang digunakan adalah kuesioner dari Tesis Visi Prima Twin Putranti (2014) tentang Hubungan Pengetahuan dan Sikap tentang Persalinan dengan Kesiapan Primigravida Menghadapi Persalinan. Nilai cronbach's alpha $(0,805)$ dan nilai $r$ tabel $(>0,600)$. Teknik analisis data yang digunakan yaitu univariat menggunakan median, nilai minimum dan maksimum, sedangkan bivariat menggunakan Uji Wilcoxon.

\section{HASIL}

Tabel 1. Nilai Kesiapan ibu dalam Menghadapi Persalinan

\begin{tabular}{cccccc}
\hline Nilai & Median & Std. Deviation & Max & Min & $95 \%$ CI \\
\hline Pre test & 49 & 3.100 & 56 & 46 & $48,74-51,06$ \\
Post test & 57 & 2.255 & 62 & 53 & $56,66-58,34$ \\
\hline
\end{tabular}

Berdasarkan tabel 3 pada pre test nilai tengah yaitu 49, nilai maksimum yaitu 56 dan nilai minimum yaitu 46. Sedangkan pada post test nilai tengah yaitu 57 , nilai maksimum yaitu 62 dan nilai minimum yaitu 53 .

Tabel 2. Uji Normalitas Kesiapan Ibu Hamil dalam menghadapi Persalinan (menggunakan ShapiroWilk)

Nilai $\quad$ Df $\quad p$ value




$\begin{array}{lll}\text { Pre test } & 30 & 0,001 \\ \text { Post test } & 30 & 0,269\end{array}$

Berdasarkan dari tabel 2, didapatkan bahwa pada pre test p-value sebesar 0,001 <0,05 sedangkan pada post test p-value sebesar 0,269 > 0,05, dapat disimpulkan bahwa distribusi tidak normal sehingga analisis bivariat menggunakan Uji Wilcoxon.

Tabel 3. Pengaruh Media Video terhadap kesiapan Ibu hamil dalam menghadapi persalinan

\begin{tabular}{llcc}
\hline & $\mathrm{N}$ & Median (min-maks) & P value \\
\hline Kesiapan sebelum penyuluhan & 30 & $49(46-56)$ & 0,000 \\
Kesiapan setelah penyuluhan & 30 & $57(53-62)$ & \\
\hline
\end{tabular}

Berdasarkan tabel 3, diperoleh $p$-value yaitu 0,000 dengan tingkat kemaknaan $\propto=0,05$ Artinya terdapat perbedaan pengaruh pendidikan kesehatan berbasis video terhadap persiapan persalinan .

\section{PEMBAHASAN}

Berdasarkan hasil penelitian ini, dari kuesioner yang peneliti bagikan pada responden, kesiapan tentang persiapan persalinan yang paling banyak tidak dipersiapkan adalah tentang calon pendonor darah dan tindakan operasi apabila ada kegawatdaruratan. Rata-rata jawaban responden saat ditanya mengenai calon pendonor darah adalah tidak mengetahui bila harus mempunyai calon pendonor darah, maka dari itu responden tidak menyiapkannya dan responden tidak rata-rata tidak mengetahui golongan darah yang sama di keluarganya. Responden paling tidak siap dengan tindakan operasi karena lebih malah dibandingkan persalinan normal.

Pernyataan paling siap adalah mengenai hari taksiran persalinan dan biaya. Responden rata-rata hafal tanggal dan bulan dimana kelahiran nanti. Sehingga responden lebih waspada akan tanda-tanda persalinan pada bulan tersebut. Lalu pernyataan paling siap yang lain yaitu mengenai biaya. Responden sudah mempersiapkan biaya jauh-jauh hari sebelum mendekati bulan kelahiran. Karena responden dan keluarga sadar biaya persalinan tidaklah murah, maka dari itu responden mempersiapkan biaya dengan menabung.

Pada penelitian ini dilakukan uji normalitas menggunakan Shapiro-Wilk didapatkan 
bahwa pada pre test p-value sebesar 0,001 <0,05 sedangkan pada post test $p$-value sebesar 0,269>0,05 maka dapat disimpulkan bahwa distribusi tidak normal sehingga menggunakan uji Wilcoxon, didapatkan $p$ value sebesar $0,00<0,05$ artinya terdapat pengaruh antara media video dengan kesiapan ibu hamil dalam menghadapi persalinan. Kesiapan merupakan bagian dalam sikap, yaitu suatu respon tertutup dari seorang individu pada sebuah rangsangan ataupun objeknya (Purbowati, Follona and Wijayanti, 2021). Pemberian pendidikan kesehatan atau informasi dapat meningkatkan sikap dan perilaku seseorang menjadi lebih baik. Mengacu dari hasil penelitiannya, bisa disimpulkan jika pemberian informasi tentang persiapan persalinan menggunakan media video dinilai mampu untuk meningkatkan kesiapan responden dalam menghadapi persalinan. Hal ini sejalan dengan penelitian (Purbowati, Follona and Wijayanti, 2021) ada perbedaan yang signifikan skor kesiapan sebelum dan setelah diberikan intervensi video dengan $(\mathrm{p}=0,012)$.

Faktor yang melandasi terciptanya sebuah sikap diantaranya wawasan, pengalaman pribadi, lingkungan, seseorang yang dipandang berpengaruh, dan media massa pernyataan dari Purbowati 2016 dikutip oleh (Purbowati, Follona and Wijayanti, 2021). Mengacu dari hasil penelitian bisa disimpulkan bahwa responden mengalami tahapan tingkat kesiapan, yaitu: tahap menerima (receiving), pada penelitian ini responden mau dan memperhatikan informasi tentang persiapan persalinan yang diberikan oleh peneliti, tahap menanggapi (responding), pada penelitian ini responden memberikan jawaban atau tanggapan terhadap informasi tentang persiapan persalinan yang dihadapkan, tahap menghargai (valuing), pada penelitian ini responden memberikan nilai yang positif terhadap informasi tentang persiapan persalinan yang diberikan seperti mengerjakan atau mendiskusikan suatu masalah terkait persiapan persalinan, dan tahap bertanggung jawab (responsible), pada tingkatan ini terjadi perubahan sikap responden menjadi lebih siap dan berani untuk menghadapi persalinan, serta reponden merasa bertanggung jawab atas semua hal yang ditentukannya ataupun risiko lainnya terkait menstruasi.

Kesiapan tidak bisa didapatkan dengan mudah dan instan. Namun dengan adanya media yang dapat digunakan berulangkali dapat membantu ibu hamil untuk lebih menyiapkan persalinan. Bidan selaku tenaga kesehatan yang menjalankan profesinya, selain mempunyai peran sebagai pemberi pelayanan juga peran sebagai pendidik dengan 
memberikan penyuluhan atau pendidikan kesehatan tentang persiapan persalinan. Setelah diberikan video terdapat hasil yang signifikan dengan terdapat perubahan kesiapan dari yang cukup lalu menjadi baik, karena pemberian pendidikan kesehatan dengan menggunakan media video dapat meningkatkan pengetahuan dan sangat memungkinkan untuk meningkatkan kesiapan ibu hamil dalam menghadapi persalinan.

Sesuai dengan hasil penelitian dari (Saban, 2017) tentang penyuluhan penggunaan video dibandingkan media leaflet pada siswi SMAN 2 Ngaglik Sleman, media video audiovisual lebih efektif dalam meningkatkan pengetahuan kesehatan dibandingkan menggunakan leaflet. Subjek penelitian yang diberikan pendidikan kesehatan menggunakan video akan lebih mudah memahami informasi karena mengaktifkan lebih banyak indra dibandingkan hanya menggunakan leaflet. Informasi dengan video ini akan menambah pemahaman ibu sehingga pengetahuan ibu dapat lebih baik.

Sesuai juga dengan teori yang mengatakan bahwa media video mempunyai banyak kelebihan diantaranya dapat diulang-ulang bila perlu menambah kejelasan, pesan yang disampaikan cepat dan mudah diingat, video dapat mendorong dan meningkatkan motivasi untuk tetap melihat. Pemberian kelas ibu hamil dengan menggunakan video, responden akan memiliki sikap lebih tertarik terhadap materi yang disampaikan dan dapat diulang-ulang setiap saat oleh responden di rumah (Sari, 2019). Pada Penelitian ini, video dibuat dalam bentuk animasi, sehingga tampilannya lebih menarik dengan bahasa yang singkat dan jelas.

Hal ini sejalan dengan penelitian (Sari, 2019) yang menjelaskan bahwa ada pemberian pendidikan kesehatan video lebih memiliki sikap yang lebih baik dibandingkan media standard yang ada. Sehingga media video lebih efektif meningkatkan pengetahuan dan sikap ibu hamil dalam menolong persalinan. Keterbatasan penelitian ini diantaranya adalah selama masa pandemi, belum aktifnya kelas ibu hamil di Puskesmas tersebut, sehingga pelaksanaan kegiatan penelitian bersamaan dengan pelayanan kesehatan lainnya, sehingga sebaiknya dilakukan pada waktu dan tempat tertentu misalnya pada pelaksanaan keklas ibu hamil, sehingga responden lebih fokus dan nyaman.

\section{KESIMPULAN}

Terdapat peningkatan nilai median, minimal dan maksimal pada kesiapan ibu hamil 
dalam menghadapi persalinan setelah diberikan pendidikan kesehatan ibu hamil melaui media video. Penggunaan media video animasi yang menarik diharapkan dapat mempermudah pemahaman responden. Terdapat pengaruh pendidikan kesehatan berbasis video terhadap kesiapan ibu hamil dalam menghadapi persalinan di UPTD Puskesmas Talun Kabupaten Cirebon Tahun 2021. Media video dapat dijadikan sebagai salah satu alternatif dalam memberikan informasi tentang persiapan persalinan pada ibu hamil.

\section{UCAPAN TERIMAKASIH}

Penulis mengucapkan terimakasih kepada Kepala Dinas Kesehatan Kabupaten Cirebon, Kepala Puskesmas Talun, dan responden yang telah membantu dalam pelaksanaan penelitian ini.

\section{DAFTAR PUSTAKA}

Ambarwati et al. (2014) 'Media Leaflet, Video Dan Pengetahuan Siswa SD Tentang Bahaya Merokok', Jurnal Kesehatan Masyarakat (e-Journal), 10(1), pp. 7-13.

Joyce Y, J. (2014) Keperawatan Maternitas Demystified. doi: 10.1016/B978-0-443-068034.00017-4.

Kemenkes (2011). Pedoman Pelaksanaan Kelas ibu hamil

Notoatmodjo, S. (2012a) Metode Penelitian Kesehatan. Jakarta: Rineka Cipta.

Purbowati, N., Follona, W. and Wijayanti, M. E. (2021) 'Pengaruh Video dan Leaflet tentang Menstruasi terhadap Kesiapan dalam Menghadapi Menarche', Jurnal Bidan Cerdas, 3(1), pp. 1-9. doi: 10.33860/jbc.v3i1.239.

Saban, S. (2017) 'Efektivitas Media Video Dan Leaflet Terhadap Pengetahuan Tentang Anemia Siswi SMAN 2 Ngaglik Sleman', Naskah Publikasi. Available at: http://digilib.unisayogya.ac.id/2982/1/NASKAH PUBLIKASI.pdf.

Sari, K. C. (2019) 'Pengaruh Media Video pada Kelas Ibu Hamil terhadap Pengetahuan Sikap dan Perilaku Pemilihan Penolong Persalinan', Journal for Quality in Women's Health, 2(2), pp. 5-15. doi: 10.30994/jqwh.v2i2.32.

SDKI (2012) 'Survei Demografi dan Kesehatan Indonesia 2012', Sdki. doi: 10.1111/j.14710528.2007.01580.x.

Susiana, S. (2019) 'Angka Kematian Ibu: Faktor Penyebab Dan Upaya Penanganannya', Pusat Penelitian Badan Keahlian DPR RI, XI.

Visi Prima Putri Putranti (2014) 'Hubungan Pengetahuan dan Sikap tentang Persalinan dengan Kesiapan Primigravida Menghadapi Persalinan’.

Yeva Yuni (2017). Gambaran Pengetahuan tentang persalinan dan Kesiapan ibu hamil dalam 
menghadapi persalinan di BPM Bidan V Kabupaten Bogor. 